University of South Florida

DIGITAL COMMONS

Digital Commons @ University of

@ UNIVERSITY OF SOUTH FLORIDA

South Florida

1987

\title{
A Bias in the Satellite-Observed Low-Level Cloud Motion Winds Over the Central Tropical Pacific
}

Gary T. Mitchum

University of Hawaii, mitchum@usf.edu

Follow this and additional works at: https://digitalcommons.usf.edu/msc_facpub

Part of the Life Sciences Commons

\section{Scholar Commons Citation}

Mitchum, Gary T., "A Bias in the Satellite-Observed Low-Level Cloud Motion Winds Over the Central Tropical Pacific" (1987). Marine Science Faculty Publications. 2076.

https://digitalcommons.usf.edu/msc_facpub/2076

This Article is brought to you for free and open access by the College of Marine Science at Digital Commons @ University of South Florida. It has been accepted for inclusion in Marine Science Faculty Publications by an authorized administrator of Digital Commons @ University of South Florida. For more information, please contact digitalcommons@usf.edu. 


\title{
A Bias in the Satellite-Observed Low-Level Cloud Motion Winds Over the Central Tropical Pacific
}

\author{
Gary T. Mitchum \\ Hawaii Institute of Geophysics, University of Hawaii, Honolulu
}

\begin{abstract}
Island wind data from the central tropical Pacific are compared with satellite-observed low-level cloud motion winds over the same area during 1976-1980. The purpose of the comparison is to investigate the effect of gaps in the satellite wind series. It is found that the distribution of the gaps is such that the resulting time series is biased from the complete time series because of undersampling of the strongest westerly and northerly wind anomalies. This bias is strong enough, at least in this geographical region, to cause difficulties in estimating accurate mean fields from the cloud motion winds alone. The gaps leading to this bias occur on time scales of days to weeks and are most common during the northern hemisphere winter. Further, the gaps can be attributed to the presence of heavy, high cloud cover typical of strong convective events. The bias follows from the fact that the wind anomalies are also strongest at these times.
\end{abstract}

\section{INTRODUCTION}

For about the last decade the National Environmental Satellite Service (NESS) has routinely provided satellite observations of low-level cloud motion winds. This technique involves using a satellite to observe low-level clouds for the purpose of inferring wind vectors at the cloud base. These data are hereinafter referred to as sawinds. The sawinds have been shown to agree reasonably with cloud base winds at a height of a kilometer or so [Hubert and Whitney [1971], Hasler et al. [1979], and others]. For the present discussion it is important to note that the sawind time series are inherently gappy. This is due to the fact that no low-level sawind data can be obtained when there are no clouds or, more importantly for this study, when the low-level clouds are obscured by higher clouds. For example, the latter situation can occur during periods of deep convection.

Many previous studies have concentrated on intercomparisons of sawinds and surface winds. The agreement between sawinds and buoy winds in the Pacific has been studied by Halpern [1978, 1979] and Halpern and Knox [1983]. Wylie and Hinton [1981, 1982] have compared sawinds with ship winds in the Indian Ocean. Most of these intercomparisons are done in order to derive algorithms which can be used to estimate surface winds from the sawind data. Sadler and Kilonsky [1985] have given a method for computing monthly mean surface winds from monthly mean sawinds using a climatological value for the shear between the two levels. Harrison and Gutzler [1986] further investigate the correction of low-level $(850 \mathrm{mbar})$ winds to obtain surface winds. Taken as a whole, these studies indicate that for periods greater than about 2 weeks, at least the zonal surface wind component can be estimated with reasonable accuracy using regression relations and empirical boundary layer corrections.

The purpose of the present study is somewhat different. The question to be addressed here concerns the effect of the irregular distribution of the data. That is, in addition to the errors generated in correcting the sawinds for the shear from the surface, there may well be errors due to the uneven sampling of the sawind series. The emphasis in this report will be on the

Copyright 1987 by the American Geophysical Union.

Paper number 7C0010.

0148-0227/87/007C-0010\$05.00 effects of the gaps in the sawind data set. In the next section the data used will be described, and an observed bias in the sawind data will be noted. The following section will quantify this observation statistically and give a more complete description of it. Finally, an example of the effect of the bias will be given, and a few suggestions concerning the use of the sawinds will be put forth.

\section{Data Description and an ApParent SAWIND BIAS}

Historical wind records from a number of Pacific islands have recently been collected and described by Luther and Harrison [1984]. Data from several of the near-equatorial stations in the central Pacific were provided by D. Luther for use in evaluating the sawind data obtained from NESS in the same area. Figure 1 shows the location of the island stations (maintained by the New Zealand Meteorological Service) used in this study. The time period covered is 1976-1980. The spatial coverage is limited by a lack of sawind data west of about the date line and a lack of island data to the east of the Line Islands. Also shown in this figure is the average number of sawind observations per day at each station. The island data sets have very few gaps and can be considered complete in contrast to the sawind data sets.

The treatment of the data series was quite simple. First, at each station the island and sawind data were used to compute daily means by simply averaging all available observations on that day. If there was no sawind observation, then that point was flagged as missing in the sawind daily series. Table 1 lists the means and standard deviations of both wind components for the island data. To aid comparisons of different stations, the island wind data components were normalized by subtracting the mean value and dividing by the standard deviation. The calculations described in the next section use these normalized series. However, calculations using data which were not normalized, and/or using the amplitude and phase of the wind vector rather than the components, were also done and led to the same conclusions. As will be seen later, it was not necessary to normalize the sawind daily mean series.

Before normalizing the island data, plots (not shown) of the two data types were inspected at each station. There was an apparent correlation between the island data and the corresponding sawinds in accord with the above mentioned studies. 


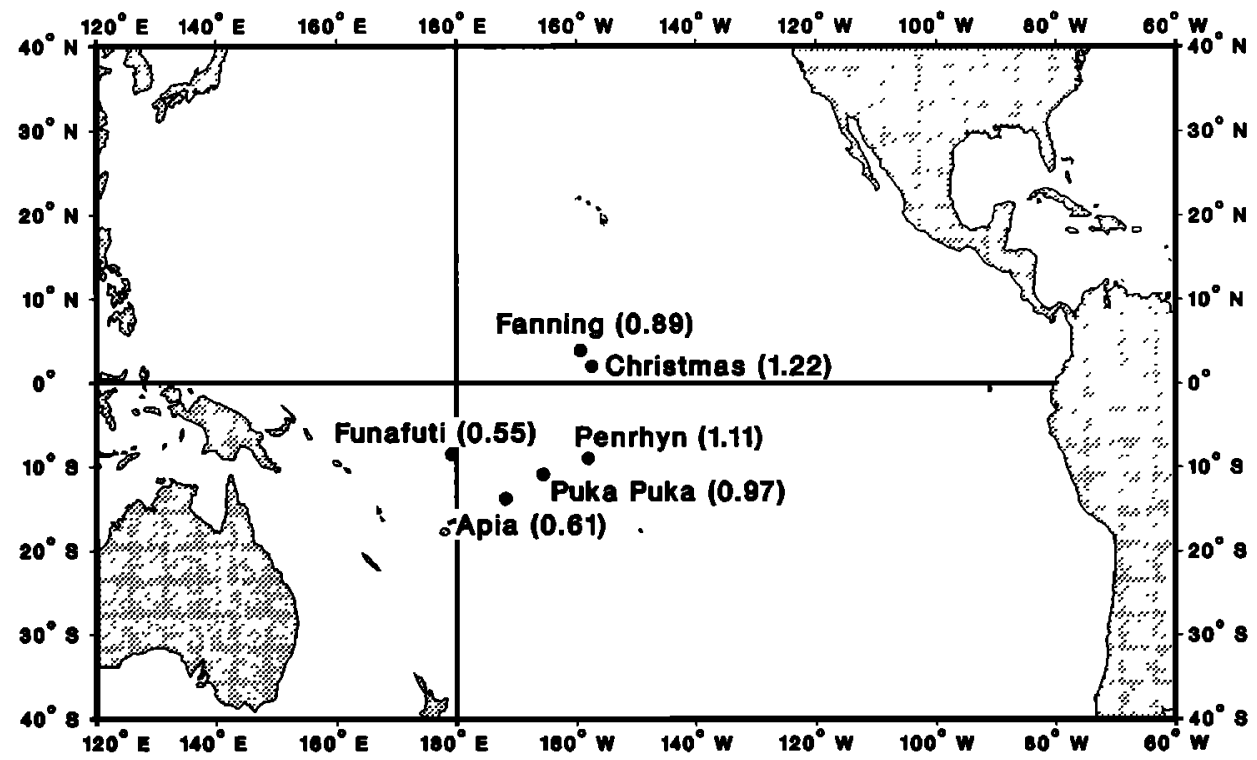

Fig. 1. Map of the Pacific showing the locations of the island wind stations used in this study. The numbers in parentheses are the total number of satellite observations at that station divided by the number of days in the study period.

However, it also seemed clear that whenever there was a strong fluctuation in the island data there was a significant likelihood that the corresponding sawind data set would have a gap. That is, if the sawind series is considered to be a "sampling" of the entire record, then the sawinds appeared to be undersampling many events having energetic fluctuations about the mean. This qualitative observation is the motivation for the present study. The remainder of this report will focus on verifying this bias quantitatively and examining how the sawind-sampling scheme affects the resulting wind data set.

Before proceeding, it should be pointed out why this observation is of possible importance. If this bias is indeed present, then an analysis procedure which uses the sawinds can produce biased results for averaged fields if it is not accounted for. A specific example of this is given in section 3.5.

\section{RESUlts}

\subsection{Quantitative Analysis of the Bias}

The analysis will begin with a description of the basic comparison technique. The idea is to statistically compare a sample of the island winds which correspond to days when the sawind data is available to samples which are chosen randomly from the complete island wind data set. If there are statistically significant differences in this comparison, then the sawind data set is deemed to be "biased" from the sawind dataset which would be realized by choosing a sample of the same size at random. The implicit assumption is that the island wind data can be used as a proxy for the sawind data for the purpose of evaluating the effect of the gaps in the sawind time series.

Note carefully that the daily sawind data series are not used in calculations but are used only to determine what the proper sample of the island wind data is. For the subsequent discussion it is important to define the term "sawind sample." The sawind sample is simply that subset of the complete island wind record which corresponds to days when there is a simultaneous sawind observation at the station of interest.

A specific example of the comparison technique can be de- scribed for illustration purposes. Suppose an estimate of the mean zonal speed at Christmas Island during the study period is desired. There are 1096 days with sawind observations from a total of 1827 days. The island wind data on these 1096 days constitute the sawind sample in this case. The mean of the island data (at Christmas) is computed for these 1096 days and found to be $-4.2 \mathrm{~m} / \mathrm{s}$. This is to be compared with the means of a set of randomly chosen samples. A sample of 1096 points is taken at random from the complete Christmas Island data set, and the mean is computed. The average of 1000 such calculations is $-3.9 \mathrm{~m} / \mathrm{s}$. Ordering the 1000 means also makes it possible to choose an upper and lower limit such that $95 \%$ of the 1000 values fall in this interval. This interval is found to be $-3.8 \mathrm{~m} / \mathrm{s}$ to $-4.1 \mathrm{~m} / \mathrm{s}$ and is defined to be a $95 \%$ confidence interval. Thus the sawind sample mean value of -4.2 $\mathrm{m} / \mathrm{s}$ would be considered biased. That is, the sample chosen by the satellite is significantly ( $95 \%$ significance level) different from what would be expected from a randomly chosen sample of the same size. For this calculation and all subsequent ones, using 1000 trials was sufficient to obtain stable results for the mean and $95 \%$ confidence interval.

For every calculation described below, this type of procedure is applied to the data at each station and also to a composite data set. The composite data set is simply all the

TABLE 1. Island Station Means and Standard Deviations

\begin{tabular}{llllll}
\hline & \multicolumn{2}{c}{ Zonal Component } & & \multicolumn{2}{c}{ Meridional Component } \\
\cline { 2 - 3 } \cline { 5 - 6 } Station & Mean & s.d. & & Mean & s.d. \\
\hline Funafuti & -2.56 & 3.59 & & 0.01 & 2.14 \\
Apia & -1.78 & 2.13 & & 0.14 & 0.93 \\
Puka Puka & -2.77 & 3.00 & & -0.65 & 1.80 \\
Penrhyn & -4.92 & 3.37 & & -1.62 & 2.75 \\
Christmas & -3.93 & 2.05 & & 0.58 & 1.36 \\
Fanning & -3.91 & 2.06 & & 0.10 & 1.63 \\
\hline
\end{tabular}

The station locations are shown in Figure 1. Units are meters per second. 
data taken together without regard to which station they are from. The idea is to temporarily give up spatial resolution in exchange for increased confidence in the results due to a larger number of degrees of freedom. Results from these composite data sets will be presented first.

\subsection{The Composite Histograms}

Possible bias in the composite samples was investigated by computing histograms of the $U$ (zonal) and $V$ (meridional) components of the normalized island data and applying the statistical technique discussed above. The results at the individual stations will be presented below. Figure 2 shows the histograms for the normalized zonal component. The solid bars show the percentage of the sawind sample which fall in each of 8 bins. The bin limits are given in the figure caption. The error bars are from random samples as illustrated above. When the top of the solid bar is below (above) the error bar, this means the sawind sample is significantly underrepresented (overrepresented) at the $95 \%$ confidence level for zonal wind speed in that bin's range. It is obvious that for the largest positive anomalies from the mean, the sawind sample is strongly underrepresented. That is, when the normal easterlies greatly weaken or reverse, the sawind data set is much more likely to have a gap. Conversely, the sawind sample is overrepresented near the mean in the bins covering 0 to -1.5 standard deviations.

Figure 3 shows the analogous calculation for the meridional component. In this case the sawind data are significantly underrepresented in the bins corresponding to the strongest negative anomalies. These correspond to strengthened northerlies. Thus at least in the area of these island stations, the distribution of the wind speeds sampled by the satellite is significantly biased from that of the complete data set. Specifically, the satellite system misses many events when the zonal

\section{Composite dataset Zonal component}

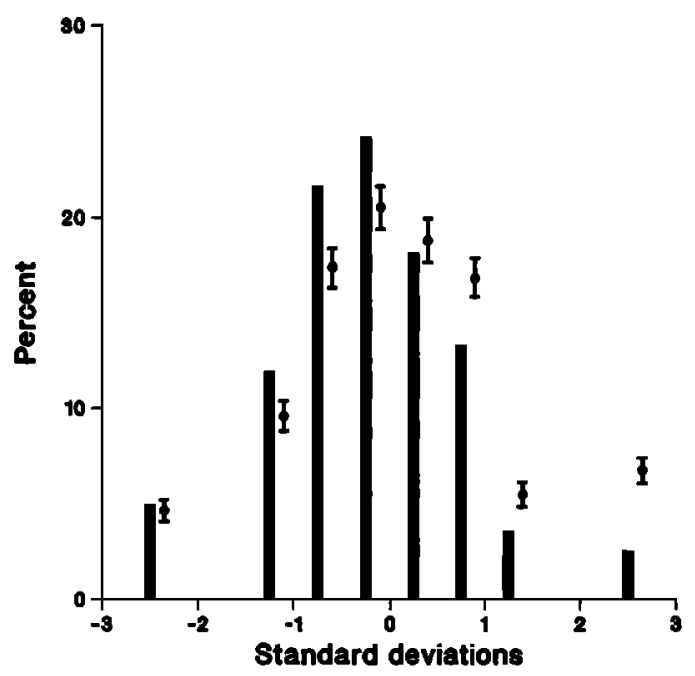

Fig. 2. Histogram showing the distribution of the normalized zonal wind component of the composite data set. The solid bars show the values for the sample of island winds corresponding to days which have a simultaneous sawind observation. The points and error bars to the right of each show the values for the random samples as described in the text (section 3.1). The bin limits are symmetric about zero. The bin limits on the positive side are 0.0 to $0.5,0.5$ to $1.0,1.0$ to 1.5 , and greater than 1.5 .

\section{Composite dataset Merldlonal component}

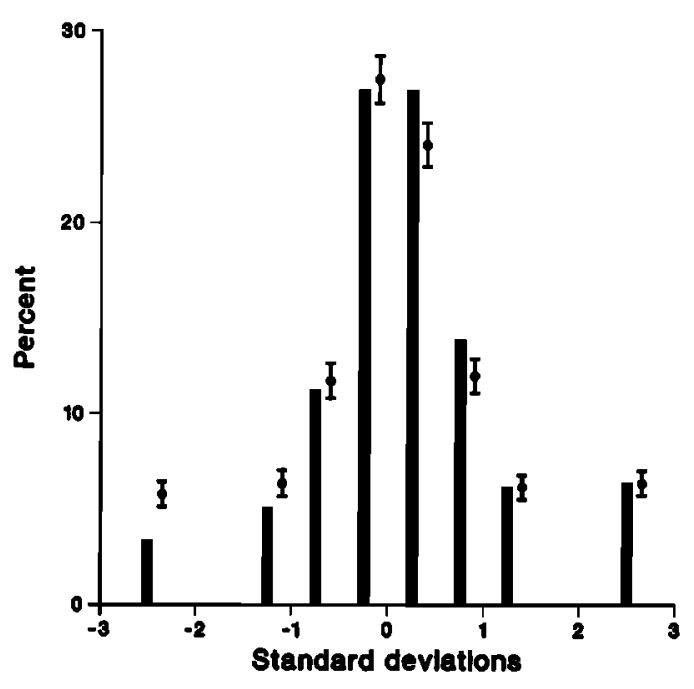

Fig. 3. As in Figure 2 but the meridional component.

winds weaken or reverse and the meridional component strengthens to the south. These histograms bear out the qualitative statement made in the introduction.

It is important to consider whether the bias seen in the composite samples is present at all the individual stations or whether it is due to a strong bias at one or two stations. Table 2 summarizes the results at the individual stations. All six stations clearly show the bias in the zonal component. Additionally, all but Christmas and Fanning show the bias in the meridional component. Thus the bias must be considered a feature of the entire study area and not just of any particular station. Several other features of the bias will now be presented.

\subsection{Time Dependence}

Figure 4 shows, for each day in the study period, how many "bias events" occur in the study area. A bias event on a given day is defined to be a strong westerly or northerly anomaly at a station which is simultaneously missing a sawind observation. A strong anomaly is defined as being greater than 1.5

TABLE 2. Summary of the Bias at the Individual Stations

\begin{tabular}{lccc}
\hline Type Anomaly & $\begin{array}{c}\text { Possible, } \\
\text { No. }\end{array}$ & $\begin{array}{c}\text { Underestimated, } \\
\text { No. }\end{array}$ & $\begin{array}{c}\text { Overestimated, } \\
\text { No. }\end{array}$ \\
\hline Strong westerly & 6 & 6 & 0 \\
Moderate westerly & 6 & 6 & 0 \\
Strong easterly & 6 & 0 & 0 \\
Moderate easterly & 6 & 0 & 3 \\
Northerly & 12 & $7^{*}$ & 0 \\
Southerly & 12 & 1 & 0 \\
\hline
\end{tabular}

Histograms analogous to those shown in Figures 2 and 3 for each individual station are summarized here. Strong and moderate anomalies are defined to be those greater than 1.5 and 1.0 to 1.5 standard deviations, respectively. For example, the first line shows that the sawind data sample at all six stations is significantly underrepresented in the bin corresponding to westerly anomalies greater than 1.5 standard deviations. For meridional anomalies the strong and moderate bins are combined and lead to 12 possible rather than six.

*All south of the equator. 

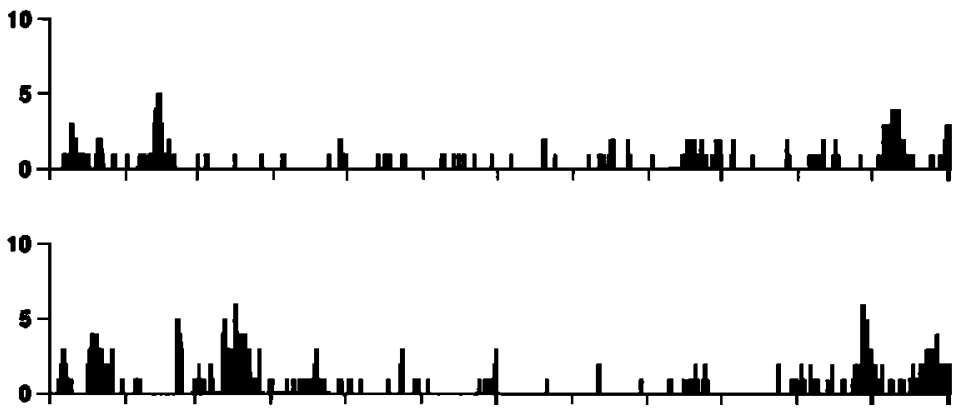

1977
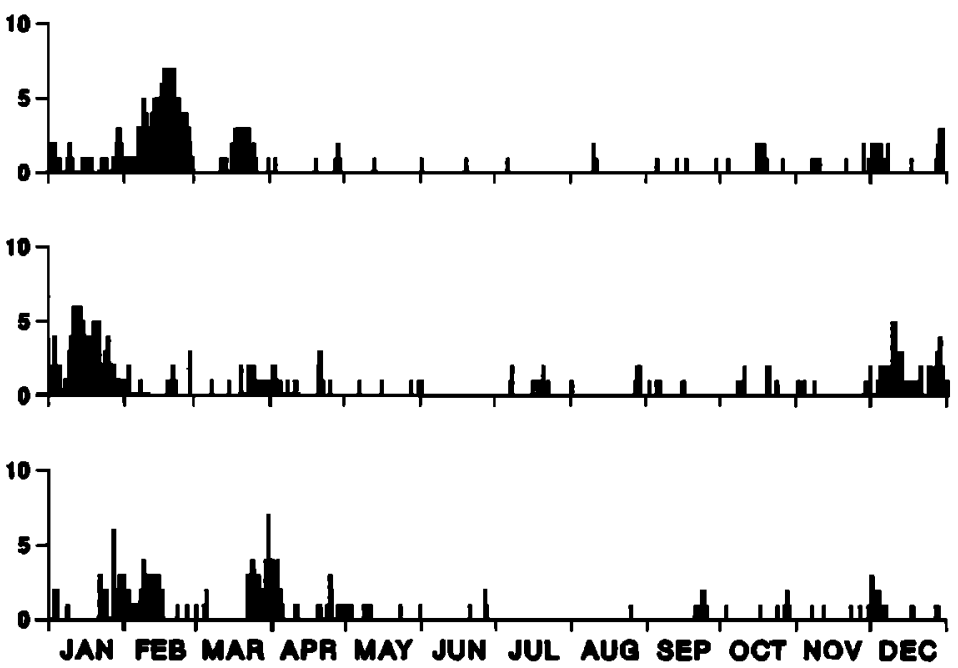

Fig. 4. The number of bias events occurring on each day during the study period. The definition of a bias event is given in section 3.3.

standard deviations from the mean. If both types of anomalies are present, both are counted. Thus it is possible to have up to 12 bias events from the 6 stations on any given day.

It is possible to estimate the time scales involved in the bias from this figure. The events occur in groups with time scales of days to weeks. There is also an obvious seasonal modulation, with many more events appearing during the northern hemisphere winter. Histograms like those shown above but computed using data separated by season also show the bias to be strong in the northern hemisphere winter and weak in the summer.

It is also instructive to consider how the bias in the daily data will affect data which are subsequently averaged in time. Calculations similar to those presented above were done using 20- and 80-day means. All of these averaged series still showed the bias. These experiments were not exhaustive, but they do imply that this bias may cause problems in estimating accurate mean fields. A specific example of this will be given shortly.

\subsection{Cloud Situation During Bias Events}

As was mentioned in the introduction, the sawind data availability depends on the cloud situation. Polar orbiter satellite images of the study area were examined on a number of days when the sawind data were missing and the underrepresented anomalies were present (see, for example, early December 1976 in Figure 4). In every case examined, the station involved was covered by high, heavy clouds typical of strong convective activity (J. Sadler, private communication, 1986). In such cases the satellite cannot observe low-level clouds and the associated winds. The bias arises, then, because of a correlation between strong convection and anomalous wind events.

\subsection{An Example of the Effect of the Bias}

How important is this bias? That is, how bad are the errors if the bias is simply ignored? One example will be given which illustrates its possible effects. Consider the question of how the bias affects a calculation of the mean and variance of the zonal wind component over the study area for the entire 5 years of data used. The mean and variance were computed using the composite island data set on days when there was a sawind observation. The mean and variance were also estimated using random samples as described above. The results (Table 3) show that the 5 -year mean is biased by nearly $1 \mathrm{~m} / \mathrm{s}$. This is because the sawind data systematically misses events with the weakest easterlies or with westerlies. The variance is also strongly biased for the same reason. To put this result in perspective, note that a stated objective for the Tropical Ocean-Global Atmosphere (TOGA) program is to compute

TABLE 3. Zonal Wind Component Mean and Variance for the Study Period 1976-1980

\begin{tabular}{lccc}
\hline & Sawind Sample & Random Sample & Differences \\
\hline Mean, $\mathrm{m} / \mathrm{s}$ & -4.16 & $-3.36 \pm 0.08$ & 0.8 \\
Variance, $(\mathrm{m} / \mathrm{s})^{2}$ & 5.9 & $7.6 \pm 0.5$ & 1.7 \\
\hline
\end{tabular}

The sawind sample is the island data only on days when there is a corresponding sawind value. The random sample values and uncertainties are computed using the technique described in section 3.1. 
monthly mean wind speeds to an accuracy of $0.5 \mathrm{~m} / \mathrm{s}$ [World Climate Programme, 1985]. However, in this study area, the sawinds alone cannot do this well even for a 5-year mean. It is also important to note that this is only one type of error. Any errors due to the correction of the sawinds to the surface level or due to the errors of measurement of the sawinds themselves will probably compound the problem.

\section{Concluding Remarks}

Summarizing, the technique of inferring winds from satellite-observed low-level cloud motions systematically fails to observe weakenings or reversals of the zonal wind component in the central tropical Pacific. Also missed is the associated strengthening of the meridional component of the wind vector at most stations. These data gaps are attributable to the presence of high clouds due to strong convection in the study area. A bias follows from the fact that the winds are also anomalous at these times. This bias is strong enough to cause difficulties in estimating mean wind fields from the satellite data alone.

Given these results, it would seem prudent to attempt similar analyses in other geographical areas where the sawind data is available and is of potential usefulness. Also, it would be desirable to evaluate the sensitivity of analysis procedures to such biases in the data. It seems likely that procedures which combine other data (e.g., ship and island winds) with the satellite data will be less affected than those which use the satellite data alone.

Acknowledgments. Doug Luther kindly provided the island wind data, and Bernie Kilonsky assisted in obtaining the cloud motion winds. Many colleagues, too numerous to mention individually, provided valuable discussions and critiques throughout the course of the work. The initial idea to investigate possible biases in the cloud motion winds arose during many enjoyable discussions with Adrian Gill when he visited the University of Hawaii in the summer of 1985 . Support was provided by the TOGA Sea Level Center under the direction of Klaus Wyrtki through NOAA Cooperative Agreement NA85ABH00032 to the Joint Institute for Marine and Atmospheric
Research (JIMAR), University of Hawaii. Hawaii Institute of Geophysics contribution 1840; JIMAR contribution 87-0130.

\section{REFERENCES}

Halpern, D., Comparison of low-level cloud motion vectors and moored buoy winds, J. Appl. Meteorol., 17, 1866-1871, 1978.

Halpern, D. H., Surface wind measurements and low-level cloud motion vectors near the intertropical convergence zone in the central Pacific Ocean from November 1977 to March 1981, Mon.Weather Rev., 107, 1525-1534, 1979.

Halpern, D., and R. A. Knox, Coherence between low-level cloud motion vectors and surface wind measurements near $0^{\circ}, 152^{\circ} \mathrm{W}$ from April 1979-February 1980, Atmos. Ocean, 21, 82-93, 1983.

Harrison, D. E., and D. S. Gutzler, Variability of monthly-averaged surface and $850 \mathrm{mb}$ winds at tropical Pacific islands, Mon. Weather Rev., 114, 285-294, 1986.

Hasler, A. F., W. C. Skillman, and W. E. Shenk, In situ aircraft verification of the quality of satellite cloud wind over oceanic regions, J. Appl. Meteorol., 15, 1481-1489, 1979.

Hubert, L. F., and L. F. Whitney, Jr., Wind estimates from geostationary satellite pictures, Mon. Weather Rev., 99, 665-672, 1971.

Luther, D. S., and D. E. Harrison, Observing long-period fluctuations of surface wind in the tropical Pacific: Initial results from island data, Mon. Weather Rev., 112, 285-302, 1984.

Sadler, J. C., and B. J. Kilonsky, Deriving surface winds from satellite observations of low-level cloud motions, J. Clim. Appl. Meteorol., 24, 758-769, 1985.

World Climate Programme, Report of the third session of the JSC/CCCO TOGA Scientific Steering Group, Scripps Institution of Oceanography, 22-26 April 1985, Rep. WCP-107, World Meteorol. Organ., Geneva, Switzerland, 1985.

Wylie, D. P., and B. B. Hinton, The feasibility of estimating largescale surface wind fields for the summer MONEX using cloud motion and ship data, Boundary Layer Meteorol., 21, 357-368, 1981.

Wylie, D. P., and B. B. Hinton, A comparison of cloud motion and ship wind observations over the Indian Ocean for the year of FGGE, Boundary Layer Meteorol., 22, 197-208, 1982.

G. T. Mitchum, Department of Oceanography, 1000 Pope Road, University of Hawaii, Honolulu, HI 96882.

(Received October 23, 1986; accepted November 17, 1986.) 